\title{
Snowmelt onset over Arctic sea ice from passive microwave satellite data: 1979-2012
}

\author{
A. C. Bliss and M. R. Anderson \\ Department of Earth and Atmospheric Sciences, University of Nebraska-Lincoln, 214 Bessey Hall, \\ Lincoln, Nebraska, 68588-0340, USA \\ Correspondence to: A. C. Bliss (acbliss3@huskers.unl.edu)
}

Received: 14 May 2014 - Published in The Cryosphere Discuss.: 6 June 2014

Revised: 15 October 2014 - Accepted: 20 October 2014 - Published: 20 November 2014

\begin{abstract}
An updated version (Version 3) of the Snow Melt Onset Over Arctic Sea Ice from SMMR (Scanning Multichannel Microwave Radiometer) and SSM/I-SSMIS (Special Sensor Microwave/Imager-Special Sensor Microwave Imager/Sounder) Brightness Temperatures data set is now available. The data record has been reprocessed and extended to cover the years 1979-2012. From this data set, a statistical summary of melt onset (MO) dates on Arctic sea ice is presented. The mean MO date for the Arctic Region is 13 May (132.5 DOY - day of year) with a standard deviation of \pm 7.3 days. Regionally, mean MO dates vary from 15 March (73.2 DOY) in the St. Lawrence Gulf to 10 June (160.9 DOY) in the Central Arctic. Statistically significant decadal trends indicate that $\mathrm{MO}$ is occurring 6.6 days decade ${ }^{-1}$ earlier in the year for the Arctic Region. Regionally, MO trends are as great as -11.8 days decade $^{-1}$ in the East Siberian Sea. The Bering Sea is an outlier and MO is occurring 3.1 days decade $^{-1}$ later in the year.
\end{abstract}

\section{Introduction}

Changes in all aspects of the Arctic cryosphere observed by satellite since late 1978 have been dramatic over the last few decades. Record low annual sea ice extent minima were recorded numerous times in the last decade, most recently in September 2012 (Parkinson and Comiso, 2013). Sea ice is becoming increasingly young and thin (Maslanik et al., 2007, 2011; Kwok et al., 2009) and thus is more susceptible to melting throughout the spring and summer months (Ngheim et al., 2007; Lindsay et al., 2009). The melt season is lengthening through changes in timing of the onset of melt in the spring and also by delaying the timing of freeze-up in the fall (Belchansky et al., 2004; Stroeve et al., 2006, 2014; Markus et al., 2009). Lengthening melt seasons increase ice volume loss in the Arctic, in particular, through earlier melt onset, which strengthens the sea ice albedo feedback loop (Stroeve et al., 2006, 2014; Markus et al., 2009).

The albedo changes on the sea ice surface that occur when melt begins allow for the absorption of solar radiation, which then increases the amount of melting that occurs within the ice-ocean system (Curry et al., 1995). An earlier date of melt onset on Arctic sea ice has a greater impact on the overall absorption of solar radiation in the ice-ocean system when compared to a lengthening of the melt season by a delay in the date of freeze-up in the fall (Perovich et al., 2007). Although no direct correlation between the melt onset date and September sea ice extent minima has been found (Wang et al., 2011), the date of melt onset in the Arctic signals the beginning of the melt season, and begins the ice-albedo feedbacks, which carry out through the remainder of the melt season (Stroeve et al., 2006; Markus et al., 2009).

Several algorithms exist to determine the date of melt onset on Arctic sea ice from passive microwave satellite observations (e.g., Smith, 1998; Drobot and Anderson, 2001; Belchansky et al., 2004; Markus et al., 2009) and also from active microwave satellite observations (e.g., Winebrenner et al., 1994; Forster et al., 2001; Kwok et al., 2003). However, melt onset dates from passive microwave observations are largely consistent for a longer time period (1979-present) than active microwave products.

We announce the release of the Snow Melt Onset Over Arctic Sea Ice from SMMR (Scanning Multichannel Microwave Radiometer) and SSM/I-SSMIS (Special Sensor 
Microwave/Imager-Special Sensor Microwave Imager and Sounder) Brightness Temperatures, Version 3 (V3) data set that is now available for download from the National Snow and Ice Data Center (NSIDC) (Anderson et al., 2014), replacing the Version 2 (V2) data set. The melt onset (MO) dates in this updated data set are calculated using the advanced horizontal range algorithm (AHRA) developed by Drobot and Anderson (2001). The data set gives an annual view of the day of year (DOY) on which MO occurred at each pixel location. The data are available at a $25 \mathrm{~km} \times 25 \mathrm{~km}$ resolution and are formatted using NSIDC's polar stereographic $304 \times 448$ pixel Northern Hemisphere grid. The data set has been reprocessed from passive microwave brightness temperatures (Tbs) to improve the consistency of data processing and extend the record of annual MO dates through the 2012 melt season. In this work, we provide a comparison of the differences between V2 and the V3 data sets, use the new V3 data set to provide an updated statistical summary of MO dates for the 1979-2012 record, and determine regional trends in the timing of MO for sea ice in the Arctic.

\section{The data set and methodology}

\subsection{AHRA melt onset date calculation}

The AHRA described by Drobot and Anderson (2001) utilizes horizontally polarized, daily-averaged Tbs from the $18 / 19$ and $37 \mathrm{GHz}$ channels. Tbs were obtained from the SMMR on board the NASA Nimbus-7 satellite platform and the series of SSM/I and the SSMIS from the Defense Meteorological Satellite Program's (DMSP) F8, F11, F13, and F17 platforms. SMMR Tbs were collected every second day, while SSM/I and SSMIS Tbs are available daily. Prior to the calculation of melt dates, the Tbs from different sensors are intercalibrated using linear regression coefficients determined from sensor overlap areas using DMSP F8 as the baseline sensor (Jezek et al., 1991; Abdalati et al., 1995; Stroeve et al., 1998; W. Meier, personal communication, October 2011).

The AHRA method (fully described by Drobot and Anderson, 2001) identifies the increase in Tbs when liquid water is introduced to the snowpack atop the sea ice (Kunzi et al., 1982; Livingstone et al., 1987). The AHRA tracks the difference between the 19 (18 GHz for SMMR Tbs) and $37 \mathrm{GHz}$ horizontally polarized Tbs at a given point (the horizontal range or HR) on a daily basis. If the HR for the day is $>4.0 \mathrm{~K}$ it is assumed that wintertime conditions exist at the point. If the HR for the day is $<-10.0 \mathrm{~K}$ then liquid water is likely present in the snowpack, causing a greater increase in the $37 \mathrm{GHz}$ channel relative to the $18 / 19 \mathrm{GHz}$ channel, and the date is recorded as the day of melt onset. Once a melt onset date is assigned at a pixel, the algorithm ignores the pixel for the remainder of the year. If the HR falls between -10.0 and $4.0 \mathrm{~K}$ the 10 days prior and 9 days following the date in question are tested. In this stage of the algorithm, two values are calculated: (1) the minimum HR from the 10 days prior is subtracted from the maximum HR for the 10 days prior and (2) the minimum HR from the 9 days following is subtracted from the maximum HR in the 9 days following. The difference between min and max HR before and after the date being tested, are compared. If the difference between Tbs during the periods prior to and following the day in question is $>7.5 \mathrm{~K}$ a melt onset date is assigned. If this value is $<7.5 \mathrm{~K}$ no melt date is determined and the algorithm continues to the next day. During the testing stage of the algorithm, a large difference between the values prior to and following the date indicates a pattern shift in the time series of Tbs, thus the AHRA determines that melt onset has occurred. A MO date is only calculated once per year at each pixel. The use of the time series window surrounding the day makes the AHRA insensitive to spurious Tbs and weather interference.

\subsection{Updates to the data set}

For Version 3 of the data set, some changes to the processing were made in addition to updating the record of annual MO dates through the 2012 melt season. The previous version of the data set (V2) was masked in such a way that a MO date was calculated only at those locations where a MO date could be calculated for every year in the 20-year period 1979-1998. This climatology mask was static and determined the pixels for which a melt date was calculated every year. The new data set (V3) no longer uses a static mask; instead, the MO dates are calculated for locations determined to be sea ice covered at the beginning of each melt season. The melt dates in a given year are calculated for pixel locations where sea ice concentration is $\geq 50 \%$ on one or both of the first 2 days with $\mathrm{Tb}$ data in March. The concentration data used here are Goddard merged sea ice concentrations available as part of the NOAA/NSIDC Arctic sea ice Climate Data Record (Meier et al., 2013). The Goddard merged sea ice concentrations are based on an algorithm that utilizes a combination of sea ice concentrations from the Bootstrap and NASA Team sea ice concentration algorithms. The beginning of March is used to represent full sea ice extent, since early March roughly corresponds to the annual maximum Arctic sea ice extent (e.g., Parkinson and Comiso, 2013). The first 2 days of data in March are used to account for days on which sea ice concentrations may be missing. Tbs were collected every second day during SMMR years (1979-1987); therefore, the sea ice concentrations used to create the ice mask for the MO dates data set may include 2 days during the period 1-5 March.

Since the sea ice mask is no longer static, the sea ice locations (especially along the ice edge) that experience MO throughout the melt season change from year to year. The annual MO date maps for 1979 and 2012 in Fig. 1 illustrate the changing sea ice mask based on the $50 \%$ sea ice concentration threshold described above and serve as sample data from the V3 data set. Some noticeable differences in the ice edge 


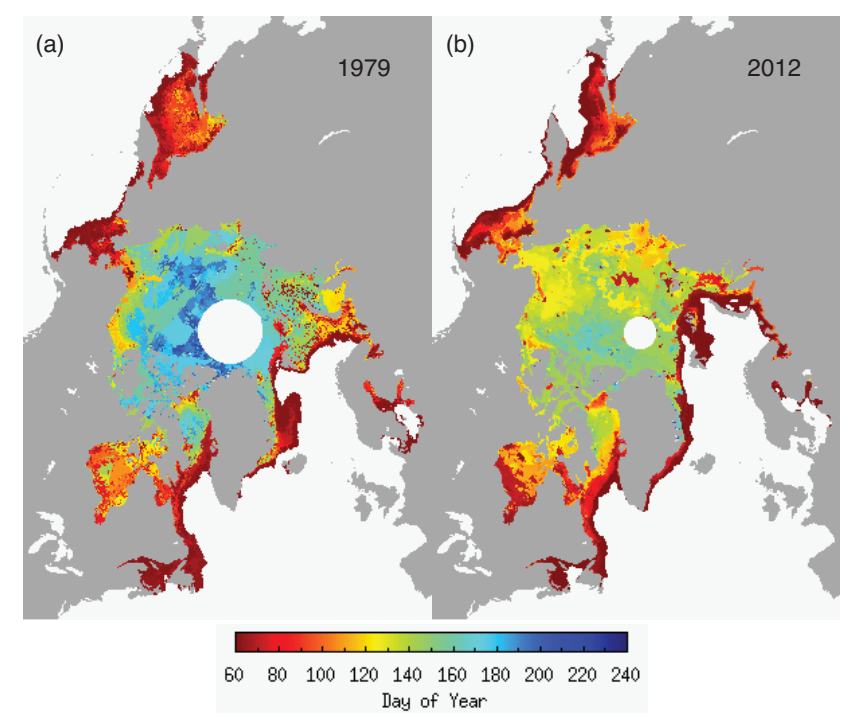

Figure 1. Annual melt onset date maps for (a) 1979 and (b) 2012 (maps available from Anderson et al., 2014).

between the 1979 and 2012 MO date maps occur in the Sea of Okhotsk and in the Baltic, Greenland, Barents, and Bering seas (Fig. 1). Due to the differences in orbit and swath width between the SMMR and SSM/I-SSMIS sensors, the data gap surrounding the North Pole (the pole hole) changes in diameter; examples of this can be seen in Fig. 1. The V2 climatology mask eliminated the difference between pole hole diameter that occurs; however, the reduction in diameter increases the amount of sea ice area for which MO is calculated, thus, increasing usefulness of the data for users who may subset the time series. Additionally, V2 of the data set included a 2-pixel buffer that eliminated coastal sea ice locations where possible uncertainties in the Tbs from land-ocean spillover can occur. Newer versions of the $\mathrm{Tb}$ data have now corrected for this spillover uncertainty (Cavalieri et al., 1999); therefore, the buffer is no longer used for V3.

As noted above, before MO is calculated, the Tbs are adjusted to improve intersensor calibration using linear regression coefficients. Version 3 of the data set extends the record using Tbs from the DMSP F17 satellite for the years 2008-2012. To be consistent with the rest of the record, the F17 Tbs are also adjusted for intercalibration with F8 Tbs using regression coefficients provided by W. Meier (personal communication, October 2011). Additionally, an erroneous application of the regression adjustment between SSM/I sensors on the DMSP F11 and F13 platforms was found and corrected for V3.

\subsection{Calculation of statistics}

All statistics reported here are calculated from pixel locations where a MO date exists in all 34 years of the data record. The sea ice locations in Fig. 2 show the MO date climatology

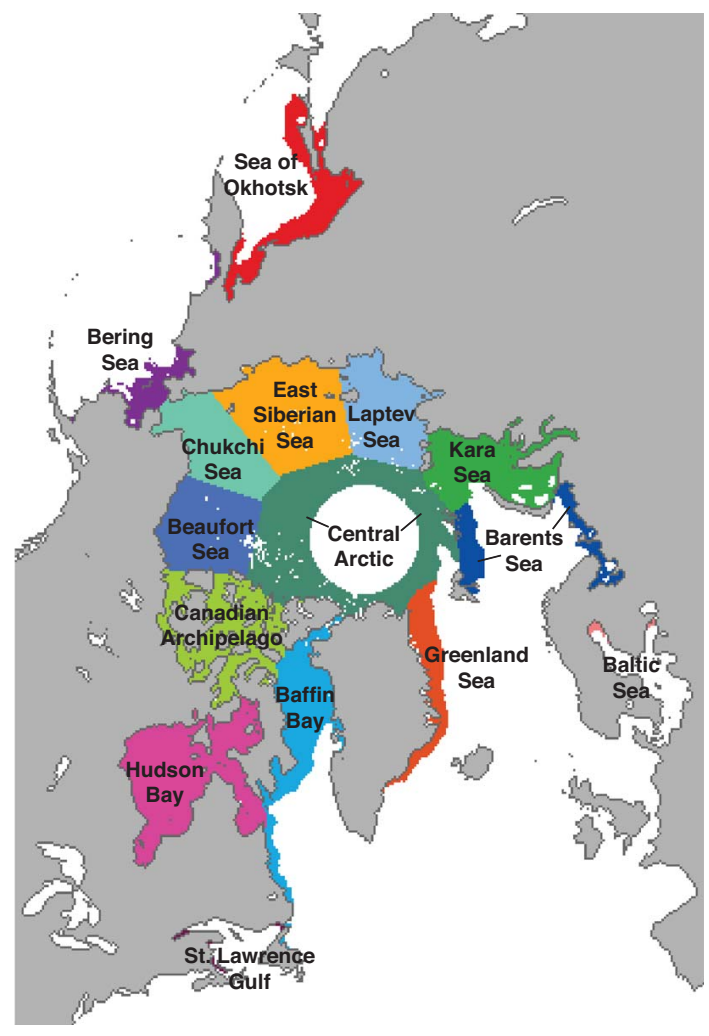

Figure 2. Melt onset date 34-year climatology and region map. White pixels indicate open water locations and locations where a MO date is not calculated for 1 or more years in the 34-year climatology. Different colors indicate the Arctic subregions used in this study.

mask used in the calculation of statistics. Grey pixels representing land and white pixels representing open water or locations that do not have a melt date for one or more years are excluded from all calculations. Statistics are calculated for all of the Arctic sea ice cover (hereafter called the Arctic Region) and for smaller subregions of the Arctic that are identified by different colors in Fig. 2. The area (in $\mathrm{km}^{2}$ ) for each subregion of the Arctic is not equal in this work because we restrict calculations of statistics to the MO date climatology mask and implicitly the sea ice extent. We divide the Arctic into common geographic regions. The regional boundaries used here are the same as used by Meier et al. (2007) except we include sea ice locations within the Baltic Sea. These regional boundaries are also similar to those of other works including Markus et al. (2009) and Parkinson et al. (1999) except that the region mask used here divides regions within the Arctic Ocean into smaller seas. The sea ice area for each region (in $\mathrm{km}^{2}$ ) is presented in Table 1. The area for the Arctic Region is the area sum of all 15 subregions. It is important to note that the statistics presented in this paper are not weighted by region size.

All maps of summary statistics including the earliest $\mathrm{MO}$ date, latest MO date, range of MO dates, mean and standard 
Table 1. Mean regional melt onset date statistics for 1979-2012.

\begin{tabular}{lrrrrrr}
\hline & $\begin{array}{r}\text { Region } \\
\text { area }\end{array}$ & $\begin{array}{r}\text { Mean MO date } \\
\left(10^{5} \mathrm{~km}^{2}\right)\end{array}$ & $\begin{array}{r}\text { Mean } \\
\text { standard } \\
\text { deviation } \\
\text { (days) }\end{array}$ & $\begin{array}{r}\text { Mean } \\
\text { earliest MO } \\
(\text { DOY })\end{array}$ & $\begin{array}{r}\text { Mean } \\
\text { latest MO } \\
\text { (DOY) }\end{array}$ & $\begin{array}{r}\text { Mean } \\
\text { range } \\
(\text { days })\end{array}$ \\
\hline Arctic Region & & & & & \\
Barents Sea & 110.0 & 13 May (132.5) & 7.3 & 121.0 & 146.5 & 25.5 \\
Kara Sea & 3.5 & 4 April (93.9) & 12.2 & 69.5 & 121.8 & 52.2 \\
Laptev Sea & 8.3 & 11 May (130.5) & 12.8 & 98.4 & 152.4 & 54.0 \\
East Siberian Sea & 8.4 & 25 May (144.9) & 11.7 & 115.9 & 167.1 & 51.2 \\
Chukchi Sea & 12.6 & 31 May (150.1) & 14.5 & 127.4 & 174.8 & 47.4 \\
Beaufort Sea & 8.2 & 17 May (136.3) & 12.7 & 112.6 & 160.6 & 48.0 \\
Canadian Archipelago & 9.0 & 28 May (148.0) & 9.9 & 130.1 & 165.3 & 35.2 \\
Central Arctic & 7.4 & 29 May (149.0) & 7.7 & 135.9 & 168.2 & 32.2 \\
Sea of Okhotsk & 17.9 & 10 June (160.9) & 9.5 & 143.8 & 181.5 & 37.7 \\
Bering Sea & 6.3 & 22 March (80.8) & 5.3 & 70.9 & 93.3 & 22.4 \\
Hudson Bay & 2.7 & 21 March (79.9) & 7.2 & 69.8 & 95.7 & 25.9 \\
Baffin Bay & 13.3 & 17 April (106.6) & 8.6 & 89.2 & 125.0 & 35.8 \\
Greenland Sea & 8.2 & 1 May (120.6) & 10.0 & 102.5 & 137.7 & 35.2 \\
Baltic Sea & 4.0 & 29 April (118.9) & 11.1 & 96.3 & 135.0 & 38.7 \\
St. Lawrence Gulf & 0.2 & 20 March (78.8) & 10.4 & 63.0 & 99.4 & 36.4 \\
\hline
\end{tabular}

deviation are calculated from the time series of MO dates at each individual pixel for 1979-2012. Regional statistics presented in Table 1 are calculated from the annual mean MO dates in each region (provided in Table S1 in the Supplement). The mean earliest MO and mean latest MO values presented in Table 1 represent the earliest and latest of the annual mean MO dates, rather than the absolute earliest and latest MO dates from the 34-year record that appear in Fig. 7a and $b$. Regional trends are calculated from the slope of the least squares linear regression best-fit line on the time series of annual mean MO dates.

\section{Comparison of V3 and V2 melt onset data}

As a comparison between the V3 and V2 MO dates, we use MO dates from the years 1983, 1992, and 2004 to illustrate the improvements and differences users will find in the updated data set. These 3 years provide examples of MO dates calculated from Tbs collected by three different sensors (SMMR in 1983, SSM/I onboard the DMSP F11 satellite in 1992, and SSM/I onboard the DMSP F13 satellite in 2004). Comparison data for all other years in the data record are provided in Figs. S1-S27 in the Supplement.

The primary differences between V3 and V2 MO dates in 1992 occur along the marginal sea ice zone (Fig. 3e, f). As described in Sect. 2.2, the V2 MO data included a 2-pixelwide buffer to reduce possible ocean-land spillover (black pixels surrounding the coastline in Fig. 3f). In V3 this buffer has been removed since spillover is not considered a problem in the Tb data and MO dates are calculated adjacent to land locations. A difference map is shown in Fig. 3g, excluding the coastline pixels. The difference map is calculated by subtracting MO dates from V2 from the V3 MO dates. Thus positive values show where V3 MO dates are later (larger) than V2 MO dates and negative values show where V2 MO dates are earlier (smaller) than V3 MO dates. The algorithm used to calculate MO dates is the same for V2 and V3, thus there are no differences in the MO dates within the sea ice pack (Fig. 3g).

Aside from the coastline pixels, the differences that do occur between 1992 MO data versions occur along the sea ice periphery in the marginal seas (Fig. 3g). These locations are a result of the different sea ice masks used to determine sea ice locations where MO should be calculated. V2 used a static climatology mask where MO dates were calculated at the same locations every year, while the V3 MO dates are calculated where the $50 \%$ sea ice concentration threshold (see Sect. 2.2) is met for that individual year. Figure $3 \mathrm{~h}$ categorizes the differences shown in Fig. $3 \mathrm{~g}$ by the version of the data in which the differing MO dates occur. Pixels along the ice edge shown in blue are new MO locations where the sea ice extended beyond the V2 climatology mask. These pixels are locations where a MO date was calculated in V3, but was excluded by the climate mask used in V2. Red pixel locations (Fig. 3h), however, are pixel locations where a MO date was calculated in V2, but not in V3. That is, any sea ice cover at the beginning of March did not meet the $50 \%$ concentration threshold and a MO date was not calculated in V3. However, in these cases the climatology mask allowed for MO to be detected in V2.

A known error in the intercalibration adjustment between Tbs obtained from the SSM/I onboard the DMSP 

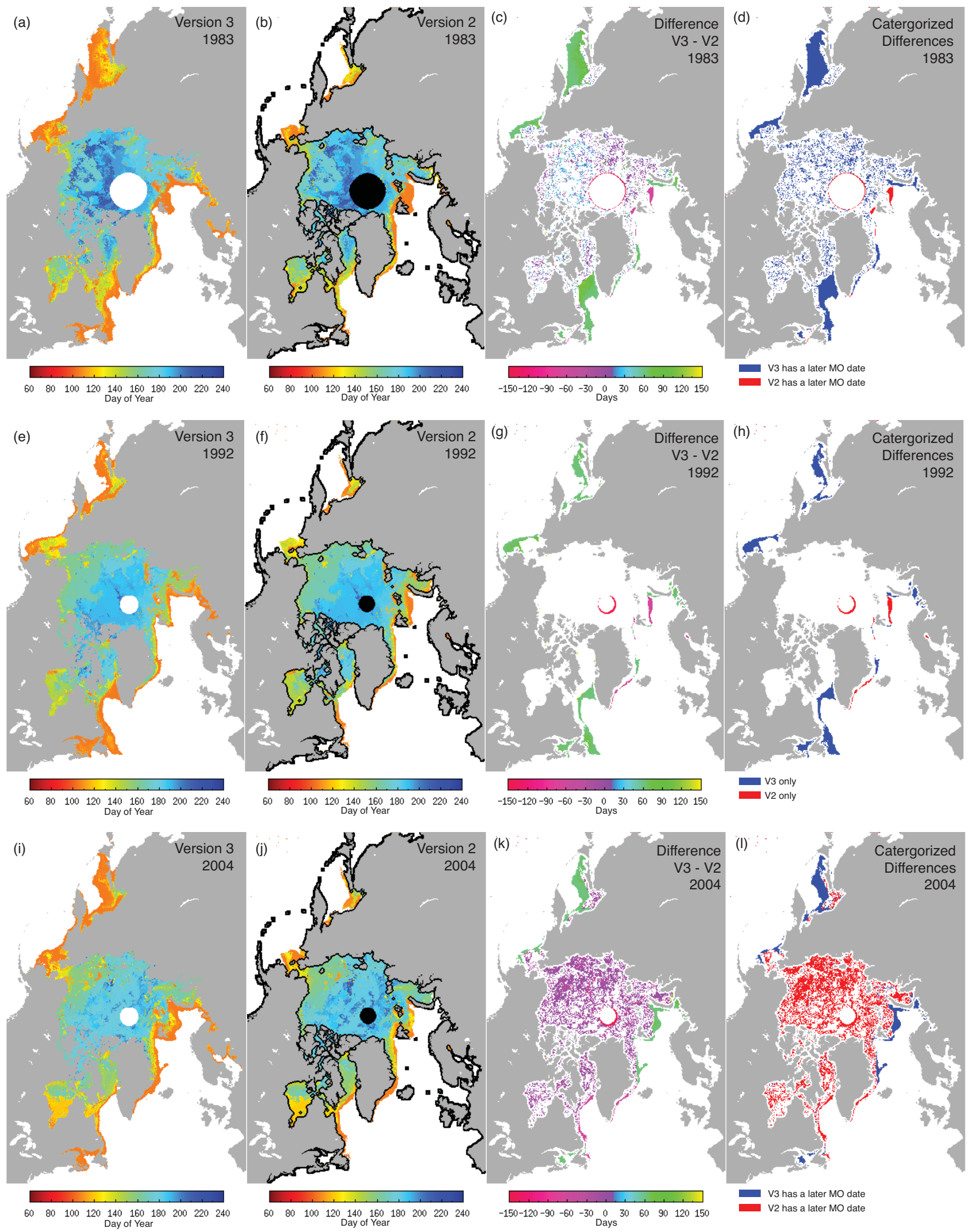

Figure 3. Comparison of V2 and V3 MO dates for 1983, 1992, and 2004. Difference maps show V2 MO dates subtracted from V3 MO dates. Categorized difference maps classify the differences between V2 and V3 MO dates by the type or cause of the differences between versions. 


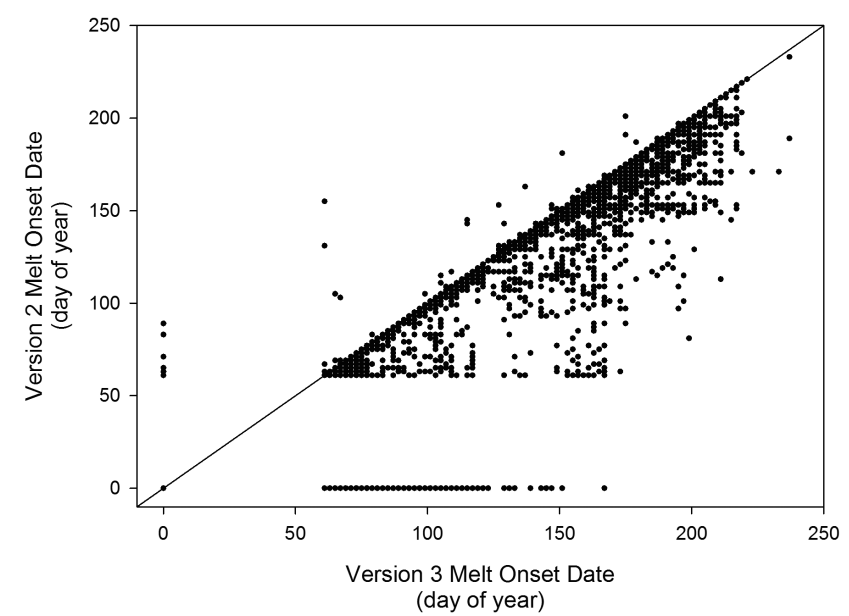

Figure 4. Scatter plot of V3 MO dates versus V2 MO dates for 1983 with $1: 1$ line.

F11 satellite and Tbs obtained from the SSM/I onboard the DMSP F13 satellite used in V2 was found and corrected for V3. As a result, 2004 and all other F13 years (1996-2007; see Figs. S16-S27) have differences in MO dates within the sea ice pack rather than only along the coastline and ice edge in other years of the record (e.g., Fig. 3k). The regression equation was adapted to correctly adjust the Tbs to the F8 baseline sensor; thus, the differences between V3 and V2 for 2004 are primarily negative (Fig. 3k) indicating that the corrected V3 MO dates are primarily earlier in the year than V2 MO dates would suggest.

Differences along the sea ice edge due to the removal of the climatology mask in V3 are present in 1983 (Fig. 3c). Additionally, differences within the sea ice pack similar to those shown in 2004 are found in 1983 (Fig. 3c) and other SMMR years (see Figs. S1-S8). In this case, the number of pixels for which there is a differing MO date for 1983 between V2 and V3 is spatially less dense than the differences found in 2004 (Fig. 3c and k); that is, there are fewer pixel locations with a differing MO date for 1983 than in 2004. It is unknown exactly why these differences in MO dates occur within the sea ice pack for the SMMR years (1979-1987) as they are unrelated to changes in the masks used for the calculation of the melt dates and the removal of the 2-pixel-buffer zone along the coastline. It is possible that some difference in the processing of V2 MO dates for SMMR Tbs occurred; however, V2 MO dates cannot be recreated, as the original programs no longer exist. The processing steps for the V3 MO dates are better known and documented and are archived at NSIDC (Anderson et al., 2014).

Figures 4-6 show scatter plots of a pixel-by-pixel comparison of the V3 MO dates versus the V2 MO dates for 1983, 1992, and 2004. In 1992, the majority of MO dates do not change between versions (Fig. 5) and the majority of the points fall along the one-to-one line. The differences in MO dates that do occur are related to the coastline and ice edge

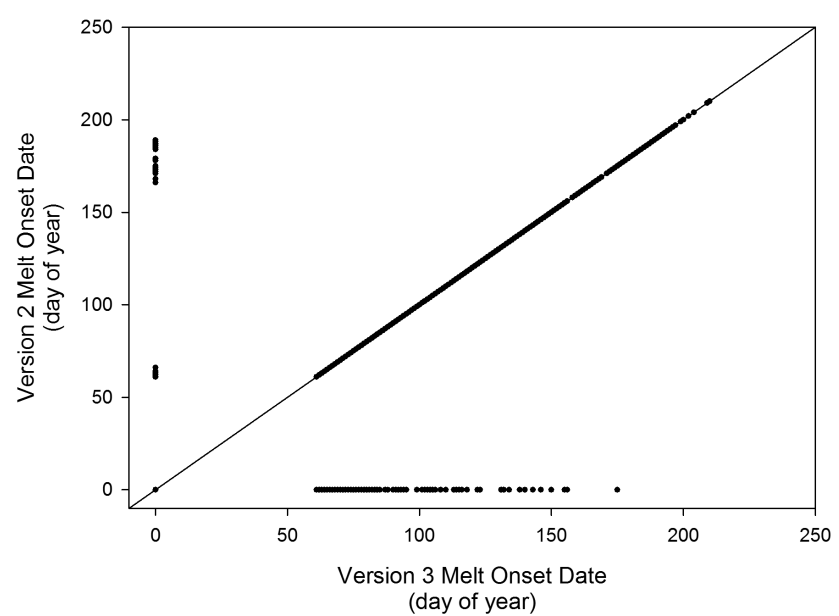

Figure 5. Scatter plot of V3 MO dates versus V2 MO dates for 1992 with $1: 1$ line.

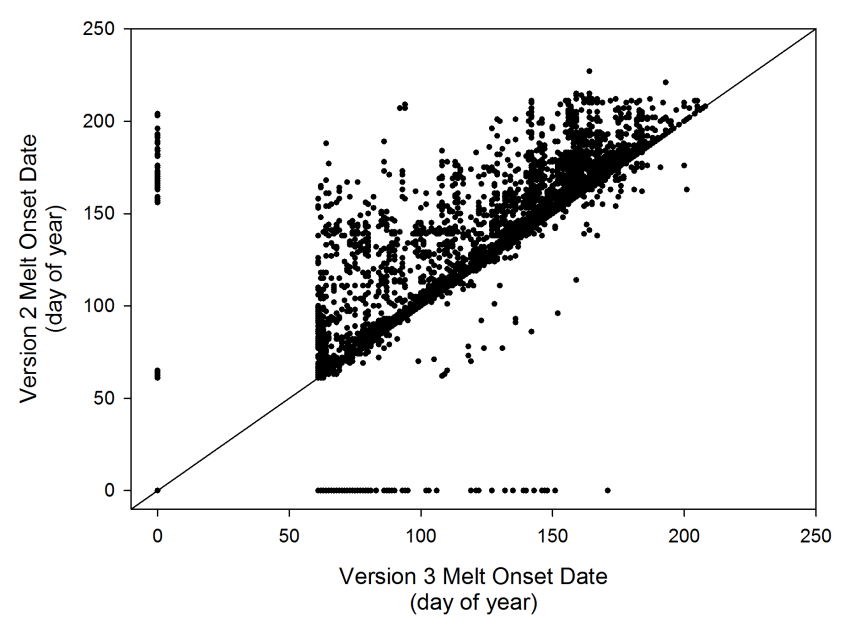

Figure 6. Scatter plot of V3 MO dates versus V2 MO dates for 2004 with $1: 1$ line.

issues described above. The differences between V2 and V3 for 2004 do not fall along the one-to-one line (Fig. 6). There is a large scatter of points to the left of the line depicting the earlier MO dates in V3 due to the intercalibration adjustment changes. In contrast to the 2004 example (Fig. 6), the largest cloud of points in 1983 falls below the one-to-one line (Fig. 4). The scattered points below the one-to-one line indicate that the differing MO dates from V3 typically occur later in the year than the V2 MO dates indicated. Similar patterns in the scatter plots occur for other years in the data record. Typically, differences from the V2 and V3 MO date comparisons in SMMR years (1979-1987) show later MO dates in V3, differences during the DMSP F8 and F11 years (1988-1995) show primarily no differences in V3 MO dates, and DMSP F13 years (1996-2007) show earlier MO dates in V3 (Figs. 4-6, S1-S26). 


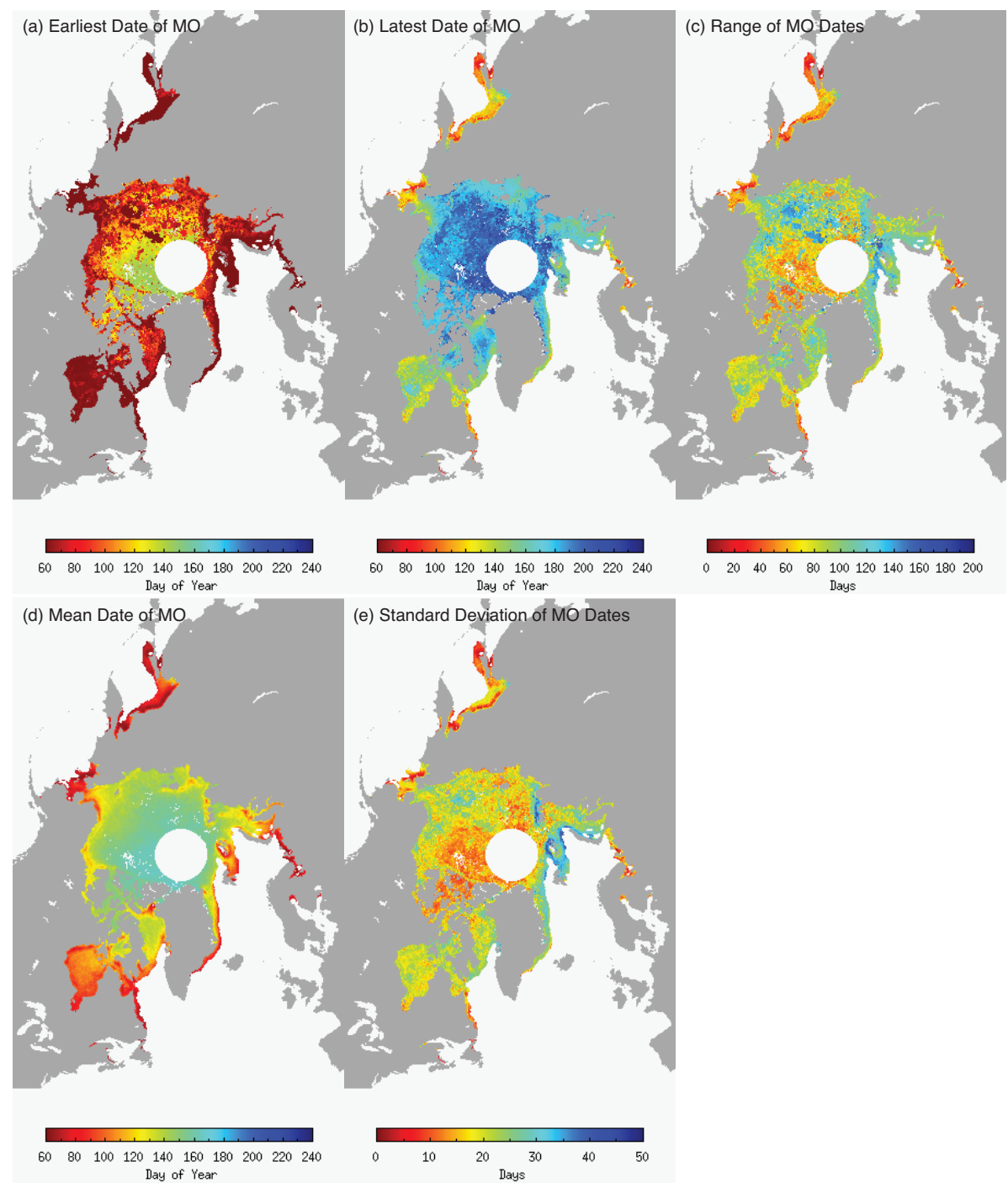

Figure 7. (a) Earliest, (b) latest, (c) range, (d) mean, and (e) standard deviation of melt onset dates for the 1979-2012 record (maps available from Anderson et al., 2014).

\section{Melt onset statistics 1979-2012}

Mean MO dates for the Arctic Region during the 34-year data record vary greatly but systematically across the extent of sea ice cover (Fig. 7); however, the mean date of MO for the Arctic Region is 13 May (132.5 DOY) with a standard deviation of \pm 7.3 days (Table 1 ). In general, the mean MO dates occur earliest at sea ice locations along the periphery of the sea ice edge and in the southernmost locations such as the Sea of Okhotsk, Bering Sea, Hudson Bay, Gulf of St. Lawrence, Greenland Sea, Baltic Sea, and Barents Sea (Table 1, Fig. 7d). This indicates a general latitudinal dependence on the timing of $\mathrm{MO}$; however, the standard deviation of MO dates can be large in portions of these early-melting regions. Regions with higher standard deviations in mean MO date have higher variability in MO timing from year to year. The regions with the highest standard deviations occur in parts of the Arctic Ocean, including: the Barents, Kara, Laptev, East Siberian, Chukchi, and Beaufort seas, with the greatest average regional standard deviation ( \pm 14.5 days) occurring in the East Siberian Sea (Table 1).

The earliest MO dates during the period 1979-2012 occur at the beginning of the melt season, in early March, for most of the peripheral regions of the sea ice area (Fig. 7a). For portions of the Central Arctic, Canadian Archipelago, and the northern portion of the Beaufort Sea, the earliest MO dates do not occur until mid-late May. The earliest MO dates in other portions of the sea ice within the Arctic Ocean occur in late March and early April (warm colors in Fig. 7a). The latest MO dates in the record for much of the sea ice regions within the Arctic Ocean occur during August, while the coastal regions of the Arctic Ocean typically have the 
latest MO dates near the end of May through June (Fig. 7b). Two distinct areas of the sea ice cover appear to have a small range (warm colors in Fig. 7c), (1) in the peripheral sea ice regions (including the Sea of Okhotsk, the Bering Sea, the Labrador Sea (in the Baffin Bay region), and the southern Barents Sea) and (2) the North American side of the Arctic including parts of the Central Arctic, the northern Beaufort Sea, and the Canadian Archipelago regions. The variability in MO dates described by both ranges and standard deviations for these locations is small; however, the timing of MO is distinctly different. In the southern, peripheral regions, where the sea ice is primarily composed of seasonal, firstyear ice, air temperatures warm to the melting point earlier in the year and early MO dates are observed. Conversely, sea ice in the Central Arctic is typically thicker, more compact, multiyear ice. Furthermore, air temperatures would warm later in the year than farther south, leading to the later mean $\mathrm{MO}$ dates observed.

The St. Lawrence Gulf and Baltic Sea regions have the earliest mean MO dates, occurring 15 March (73.2 DOY) and 20 March (78.8 DOY), respectively, although both areas are small $\left(0.1 \times 10^{5}\right.$ and $\left.0.2 \times 10^{5} \mathrm{~km}^{2}\right)$ (Table 1$)$. Other regions with relatively early mean MO dates (Table 1 ) are the Bering Sea, 21 March (79.9 DOY); the Sea of Okhotsk, 22 March (80.8 DOY); and the Barents Sea, 4 April (93.9 DOY). However, it is important to note that the early-melting sea ice in the Barents Sea is located in the southern, coastal portion of the region, while the sea ice in the northern half of the Barents, adjacent to the Central Arctic region, melts at a later date (Fig. 7d). The other peripheral and southern regions including: Hudson Bay, Baffin Bay, and the Greenland Sea have a mean MO date which occurs in the latter half of April. The remaining regions are located within the Arctic Ocean and have mean MO dates that range from 11 May (130.5 DOY) in the Kara Sea to 10 June (160.9 DOY) in the Central Arctic region (Table 1).

The mean MO dates for many of the subregions within the Arctic Ocean (Table 1) are comparable to mean early melt onset dates for 1979-2012 reported by Stroeve et al. (2014) and based on the Markus et al. (2009) method for determining MO. In general, the mean MO dates from this work occur earlier in the year than those reported by Stroeve et al. (2014) with the exception of the Central Arctic region. The mean MO dates for the East Siberian, Chukchi, and Beaufort seas and the Canadian Arctic Archipelago and Central Arctic vary from the Stroeve et al. (2014) means by 6.5 days in the Chukchi Sea to as little as 0.6 days in the Central Arctic region. In peripheral sea ice regions, the differences between mean MO dates from this work and Stroeve et al. (2014) early melt onset dates increase to as much as 30.6 days for the Barents Sea region. Given differences in the melt onset algorithms and data processing used here and in the Markus et al. (2009) method, particularly with respect to how the sea ice boundary is determined using sea ice concentrations in each method, it is expected that the greatest differences in MO statistics will occur in marginal ice zones.

MO dates can vary widely from year to year in Arctic subregions depending on when the air temperatures in different regions reach the melting point. Although, on average, there is latitudinal dependence on timing of MO, springtime weather conditions and temperature anomalies are important for explaining the year-to-year variability in MO timing for much of the sea ice within the Arctic Ocean (Anderson and Drobot, 2001; Belchansky et al., 2004; Wang et al., 2011; Markus et al., 2009). Springtime weather conditions, including cyclonic activity, can have an influence on the air temperatures and the surface energy budget of the sea ice through the trapping of longwave heat when conditions are cloudy or through increased incoming shortwave radiation when conditions are cloud-free and the sun rises in spring.

\section{Trends in melt onset dates}

Trends in the time series of annual mean MO dates indicate that $\mathrm{MO}$ is occurring earlier in the year for the majority of Arctic sea ice over the 1979-2012 data record (Fig. 8). For the Arctic Region, a statistically significant trend (99\% confidence level) of -6.6 days decade $^{-1}$ exists, indicating that MO is occurring earlier in the year in recent years when compared to the earliest years of the data record. Statistically significant negative trends also exist for subregions of the Arctic Ocean including: the Barents, Kara, Laptev, East Siberian, Chukchi, and Beaufort seas, and the Canadian Archipelago and the Central Arctic region (99\% confidence level). These trends range from -4.6 days decade ${ }^{-1}$ in the Canadian Archipelago to -11.8 days decade $^{-1}$ in the East Siberian Sea. $R^{2}$ values vary, but are strongest for the Arctic Region and the Central Arctic where the $R^{2}$ value is at least 0.76 (Fig. 8). Statistically significant trends also exist in the Bering Sea and Baffin Bay although at a $95 \%$ confidence level with weak $R^{2}$ values (Fig. 8). Southerly, peripheral regions of the sea ice where the mean MO dates occur earliest, as described in Sect. 4, tend to have very weak $R^{2}$ relationships and insignificant trends, although the trend is negative for nearly all regions.

An interesting finding to note is the statistically significant (95\% confidence level) positive trend occurring in the Bering Sea. The Bering Sea is the only region of sea ice that shows a trend towards later MO dates through the data record. The relationship is weak $\left(R^{2}\right.$ of 0.18$)$ and the area of sea ice in the region is small $\left(2.7 \times 10^{5} \mathrm{~km}^{2}\right)$, however, this region is showing an anomalous change in MO that is different from all other regions. Calculations for these trends and statistics are normalized to locations where MO dates exist in all years of the data record; however, the ice edge in this data set changes from year to year with the extent of sea ice at the beginning of March. Therefore it is interesting to note that the sea ice cover is actually more extensive in the Bering Sea in recent 

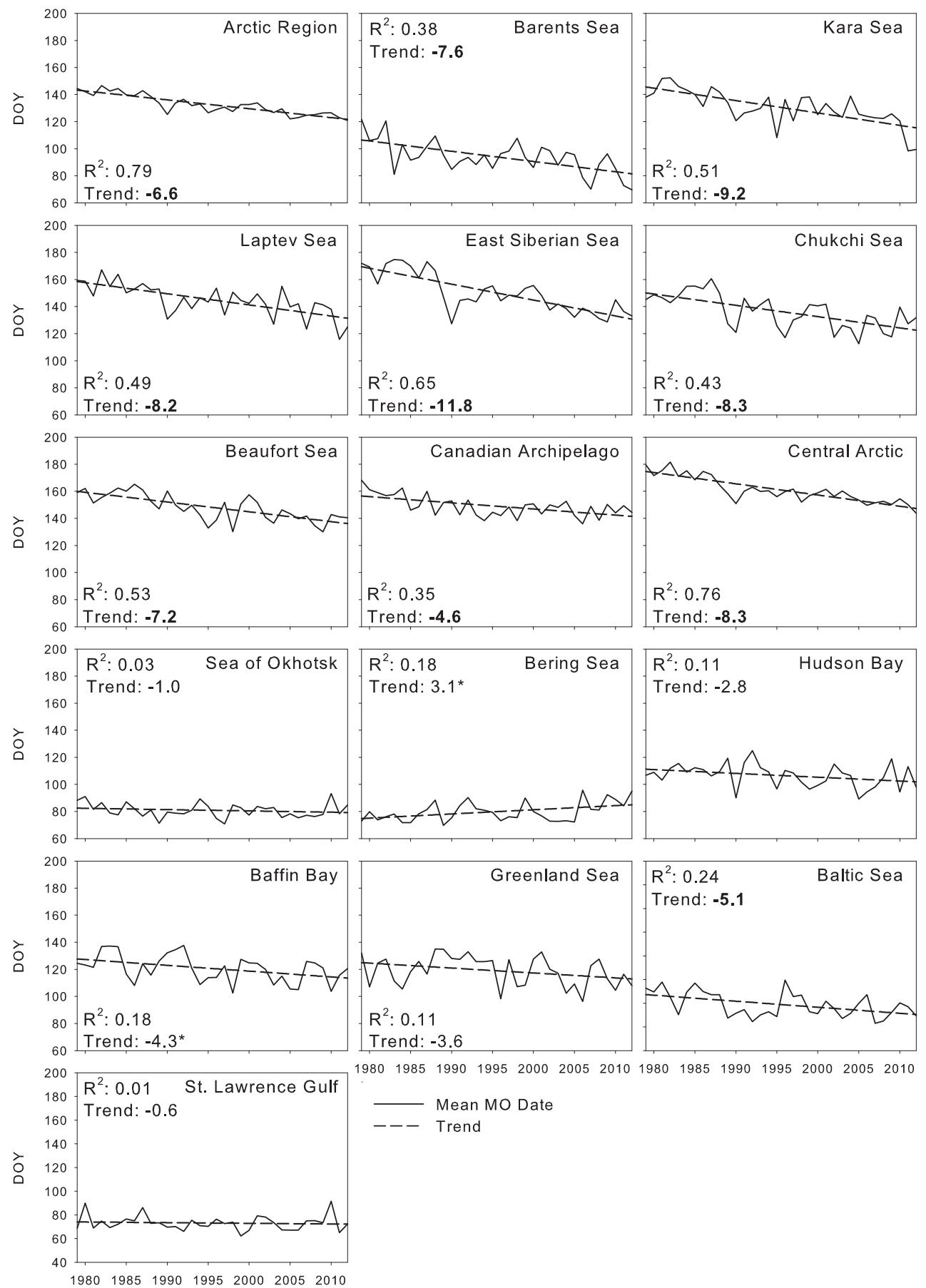

Figure 8. Time series of annual mean MO date and least squares linear regression trend for the Arctic Region and subregions. The $R^{2}$ value and decadal trend (days decade ${ }^{-1}$ ) are shown for each region. Bold trends are statistically significant at a $99 \%$ confidence level. An * indicates statistically significant trends at a $95 \%$ confidence level.

years than in the earliest years of the data record as noted by the positive yearly trend in sea ice extent described by Cavalieri and Parkinson (2012). The sea ice extent trend is apparent and complementary to the positive trend in V3 MO dates. For an example of this, see Fig. 1, where Bering Sea ice extent (using the $50 \%$ concentration threshold) is greater in 2012 than in 1979.

The MO dates presented here are similar to the "early melt onset" dates determined by Markus et al. (2009) although differences in melt dates reported by both works occur due to differences in data processing. Table 2 provides a comparison 
Table 2. Comparison of trends in V3 mean MO date with other reported trends (in days decade ${ }^{-1}$ ). Numbers in bold indicate statistical significance.

\begin{tabular}{llll}
\hline & $\begin{array}{l}\text { Mean MO } \\
\text { date trend } \\
(1979-2012)\end{array}$ & $\begin{array}{l}\text { Stroeve et al. } \\
(2014) \\
\text { early melt } \\
\text { onset trend } \\
(1979-2013)\end{array}$ & $\begin{array}{l}\text { Howell et al. } \\
(2009) \\
\text { melt onset } \\
\text { trend } \\
(1979-2008)\end{array}$ \\
\hline Arctic Region & $-\mathbf{6 . 6}$ & $-\mathbf{1 . 9}$ & - \\
Barents Sea & $\mathbf{- 7 . 6}$ & $-\mathbf{7 . 1}$ & - \\
Kara Sea & $\mathbf{- 9 . 2}$ & $-\mathbf{5 . 2}$ & - \\
Laptev Sea & $\mathbf{- 8 . 2}$ & $-2.8^{*}$ & - \\
East Siberian Sea & $\mathbf{- 1 1 . 8}$ & -1.8 & - \\
Chukchi Sea & $\mathbf{- 8 . 3}$ & -1.6 & - \\
Beaufort Sea & $\mathbf{- 7 . 2}$ & $-2.4^{*}$ & - \\
Canadian Archipelago & $\mathbf{- 4 . 6}$ & -1.0 & $-3.1^{*}$ \\
Central Arctic & $\mathbf{- 8 . 3}$ & $-\mathbf{2 . 5}$ & - \\
Sea of Okhotsk & -1.0 & 1.9 & - \\
Bering Sea & $3.1^{*}$ & 1.4 & - \\
Hudson Bay & -2.8 & $-3.3^{*}$ & - \\
Baffin Bay & $-4.3^{*}$ & $-3.3^{*}$ & - \\
Greenland Sea & -3.6 & $-\mathbf{5 . 5}$ & - \\
Baltic Sea & $-\mathbf{5 . 1}$ & - & - \\
St. Lawrence Gulf & -0.6 & - & - \\
\hline
\end{tabular}

Bold indicates statistical significance at the $99 \%$ confidence level. $\mathrm{An} *$ indicates statistical significance at the $95 \%$ confidence level.

of trends in the mean MO dates presented here and early melt onset trends reported by Stroeve et al. (2014), an update to the Markus et al. (2009) melt season length analysis. In general, the direction of trends towards earlier melt onset is in agreement for most regions (except for the Sea of Okhotsk). However, for some regions including the Arctic Region, the Laptev, East Siberian, and Chukchi seas, the magnitudes of the trends are different by 5 days decade $^{-1}$ or larger (Table 2). The greatest magnitude difference in trends occurs for the East Siberian Sea where a 10 days decade $^{-1}$ difference between trends is observed, however, the Stroeve et al. (2014) trend is not statistically significant. Similar statistically significant trends do exist for the Barents and Kara seas and Baffin Bay where the difference in trends is $\leq 4$ days decade ${ }^{-1}$. Another comparison can be made with the melt onset trend for the Canadian Arctic Archipelago determined by Howell et al. (2009), which reported a statistically significant trend of -3.1 days decade ${ }^{-1}$. The early melt onset trend for the Canadian Arctic Archipelago determined by Stroeve et al. (2014) is -1.0 days decade ${ }^{-1}$ (not statistically significant), while the trend for the V3 mean MO dates reported here is -4.6 days decade ${ }^{-1}$ (99\% confidence level).

Each method for determining trends in MO dates produces a different value due to differences in the algorithms and data processing steps used to produce the melt dates. For example, both the AHRA method used here and the Markus et al. (2009) method attempt to remove noise in the Tb data that could give erroneous melt dates. The AHRA method utilizes a 10-day time series window (described in Sect. 2.1) to remove spurious Tbs, likely the result of weather effects, which could indicate a MO date that is too early in the season. The Markus et al. (2009) method determines if a calculated melt onset date is valid by comparing the 8 surrounding pixels to test for spatial homogeneity. Furthermore, sea ice concentrations are used differently to determine the extent of sea ice in each method. The AHRA method relies on a $50 \%$ sea ice concentration threshold at the beginning of the melt season in March, while the Markus et al. (2009) method considers pixels with concentrations greater than $80 \%$ for fewer than 5 days during the year to be ice-free. The differences in the ice edge in each method as a result of these differing thresholds likely contribute considerably to differences in the statistics for marginal ice zones when calculated over a set regional boundary.

Despite these differences, various methods for determining MO dates show a significant trend towards increasingly early MO for the majority of Arctic sea ice, in agreement with the works of others (e.g., Stroeve et al., 2006, 2014; Markus et al., 2009). Earlier MO on sea ice increases the amount of solar radiation that can be absorbed by the ice-ocean system by reducing surface albedo during the time of the year when solar radiation is greatest (Perovich et al., 2007). Increased absorption of solar radiation during the spring can lead to increased heating in the Arctic, extensive loss of sea ice volume, and a delay in freeze-up following the melt season (Stroeve et al., 2014).

\section{Summary}

We have described an updated record of MO dates over Arctic sea ice that is now available for download from NSIDC (Anderson et al., 2014). This new data set utilizes the AHRA method for calculating the date of MO from passive microwave satellite data, which has improved consistency and been updated to include recent data from the SSMIS satellite sensor through 2012.

Based on this 34-year record of MO dates on Arctic sea ice we have shown that typically the sea ice periphery and southerly-located seas experience MO early in the year during the months of March and April, while northerly locations, in the central and western Arctic Ocean, experience MO in mid-late May. However, increased variability in regions within the Arctic Ocean shows that there is considerable year-to-year variability in MO timing which is attributed to variability in springtime weather conditions.

The 34-year record of MO dates shows significant, negative trends for the majority of the Arctic that indicate earlier MO. These trends in MO are on par with the warming trends observed in the Arctic over recent decades and the overall reduction of sea ice volume. However, the positive trend in the Bering Sea indicates the regional nature of MO timing and the need for more investigation into the variability of 
regional-scale atmospheric conditions surrounding the timing of MO.

\section{The Supplement related to this article is available online at doi:10.5194/tc-8-2089-2014-supplement.}

Author contributions. A. C. Bliss and M. R. Anderson collaborated on the ideas presented in this manuscript and in generation of data for Table 1 and Fig. 8. M. R. Anderson produced maps for Fig. 3 and created plots for Figs. 4-6 and S1-S27. A. C. Bliss created Fig. 2 and wrote the initial draft of this manuscript with review and editing provided by M. R. Anderson.

Acknowledgements. The Snow Melt Onset Over Arctic Sea Ice from SMMR and SSM/I-SSMIS Brightness Temperatures, Version 3 data set is available from NSIDC, Boulder, Colorado, USA (http://nsidc.org/data/docs/daac/nsidc0105_ arcticsnowmeltonset_dates.gd.html).

This work was supported by NASA MEaSUREs award NNX08AP34A. The authors thank W. Meier for providing regression coefficients used in the development of this data set and two reviewers for their constructive comments.

Edited by: J. Stroeve

\section{References}

Abdalati, W., Steffen, K., Otto, C., and Jezek, K. C.: Comparison of Brightness Temperatures from SSMI Instruments on the DMSP F8 and F11 Satellites for Antarctica and the Greenland Ice Sheet, Int. J. Remote Sens., 16, 7, 1223-1229, doi:10.1080/01431169508954473, 1995.

Anderson, M. R. and Drobot, S. D.: Spatial and temporal variability in snowmelt onset over Arctic sea ice, Ann. Glaciol., 33, 74-78, 2001.

Anderson, M. R., Bliss, A. C., and Drobot, S. D.: Snow melt onset over Arctic sea ice from SMMR and SSM/I-SSMIS brightness temperatures, Version 3, 1979-2012, NASA DAAC at 15 the National Snow and Ice Data Center, Boulder, Colorado, USA, available at: http://nsidc.org/data/nsidc-0105.html, last access: 2 June 2014.

Belchansky, G. I., Douglas, D. C., and Platonov, N. G.: Duration of the Arctic sea ice melt season: regional and interannual variability 1979-2001, J. Climate, 17, 67-80, doi:10.1175/15200442(2004)017<0067:DOTASI>2.0.CO;2, 2004.

Cavalieri, D. J. and Parkinson, C. L.: Arctic sea ice variability and trends, 1979-2010, The Cryosphere, 6, 881-889, doi:10.5194/tc6-881-2012, 2012.

Cavalieri, D. J., Parkinson, C., Gloersen, P., Comiso, J., and Zwally, H. J.: Deriving long-term time series of sea ice cover from satellite passive-microwave multisensor data sets, J. Geophys. Res., 104, 15803-15814, doi:10.1029/1999JC900081, 1999.

Curry, J. A., Schramm, J. L., and Ebert, E. E.: Sea ice-albedo climate feedback mechanism, J. Climate, 8, 240-247, doi:10.1175/1520-0442(1995)008<0240:SIACFM>2.0.CO;2, 1995.
Drobot, S. D. and Anderson, M. R.: An improved method for determining snowmelt onset dates over Arctic sea ice using Scanning Multichannel Microwave Radiometer and Special Sensor Microwave/Imager data, J. Geophys. Res., 106, 24033-24049, doi:10.1029/2000JD000171, 2001.

Forster, R. R., Long, D. G., Jezek, K. C., Drobot, S. D., and Anderson, M. R.: The onset of Arctic sea-ice snowmelt as detected with passive- and active-microwave remote sensing, Ann. Glaciol., 33, 85-93, doi:10.3189/172756401781818428, 2001.

Howell, S. E. L., Duguay, C. R., and Markus, T.: Sea ice conditions and melt season duration variability within the Canadian Arctic Archipelago: 1979-2008, Geophys. Res. Lett., 36, L10502, doi:10.1029/2009GL037681, 2009.

Jezek, K. C., Merry, C., Cavalieri, D., Grace, S., Bedner, J., Wilson, D., and Lampkin, D.: Comparison between SMMR and SSM/I passive microwave data collected over the Antarctic ice sheet, Byrd Polar Research Center Technical Report no. 91-03, The Ohio State University, Columbus, Ohio, USA, 1991.

Kunzi, K. F., Patil, S., and Rott, H.: Snow-cover parameters retrieved from Nimbus-7 Scanning Multichannel Microwave Radiometer (SMMR) data, IEEE T. Geosci. Remote, 4, 452-467, doi:10.1109/TGRS.1982.350411, 1982.

Kwok, R., Cunningham, G. F., and Nghiem, S. V.: A study of melt onset in RADARSAT SAR imagery, J. Geophys. Res., 108, 3363, doi:10.1029/2002JC001363, 2003.

Kwok, R., Cunningham, G. F., Wensnahan, M., Rigor, I., Zwally, H. J., and Yi, D.: Thinning and volume loss of the Arctic Ocean sea ice cover: 2003-2008, J. Geophys. Res., 114, C07005, doi:10.1029/2009JC005312, 2009.

Lindsay, R. W., Zhang, J., Schweiger, A., Steele, M., and Stern, H.: Arctic sea ice retreat in 2007 follows thinning trend, J. Climate, 22, 165-176, doi:10.1175/2008JCLI2521.1, 2009.

Livingstone, C. E., Singh, K. P., and Gray, L.: Seasonal and regional variations of active/passive microwave signatures of sea ice, IEEE T. Geosci. Remote, 2, 159-172, doi:10.1109/TGRS.1987.289815, 1987.

Markus, T., Stroeve, J. C., and Miller, J.: Recent changes in Arctic sea ice melt onset, freezeup, and melt season length, J. Geophys. Res., 114, C12024, doi:10.1029/2009JC005436, 2009.

Maslanik, J., Drobot, S., Fowler, C., Emery, W., and Barry, R.: On the Arctic climate paradox and the continuing role of atmospheric circulation in affecting sea ice conditions, Geophys. Res. Lett., 34, L03711, doi:10.1029/2006GL028269, 2007.

Maslanik, J., Stroeve, J., Fowler, C., and Emery, W.: Distribution and trends in Arctic sea ice age through spring 2011, Geophys. Res. Lett., 38, L13502, doi:10.1029/2011GL047735, 2011.

Meier, W. N., Stroeve, J., and Fetterer, F.: Wither Arctic sea ice? A clear signal of decline regionally, seasonally and extending beyond the satellite record, Ann. Glaciol., 46, 428-434, doi:10.3189/172756407782871170, 2007.

Meier, W. N., Fetterer, F., Savoie, M., Mallory, S., Duerr, R., and Stroeve, J.: NOAA/NSIDC climate data record of passive microwave sea ice concentration, Version 2, National Snow and Ice Data Center, Boulder, Colorado, USA, doi:10.7265/N55M63M1, 2013.

Nghiem, S. V., Rigor, I. G., Perovich, D. K., Clemente-Colón, P., Weatherly, J. W., and Neumann, G.: Rapid reduction of Arctic perennial sea ice, Geophys. Res. Lett., 34, L19504, doi:10.1029/2007GL031138, 2007. 
Parkinson, C. L. and Comiso, J. C.: On the 2012 record low Arctic sea ice cover: combined impact of preconditioning and an August storm, Geophys. Res. Lett., 40, 1356-1361, doi:10.1002/grl.50349, 2013.

Parkinson, C. L., Cavalieri, D. J., Gloersen, P., Zwally, H. J., and Comiso, J. C.: Arctic sea ice extents, areas, and trends, 1978-1996, J. Geophys. Res., 104, 20837-20856, doi:10.1029/1999JC900082, 1999.

Perovich, D. K., Nghiem, S. V., Markus, T., and Schweiger, A.: Seasonal evolution and interannual variability of the local solar energy absorbed by the Arctic sea ice-ocean system, J. Geophys. Res., 112, C03005, doi:10.1029/2006JC003558, 2007.

Smith, D. M.: Observation of perennial Arctic sea ice melt and freeze-up using passive microwave data, J. Geophys. Res., 103, 27753-27769, doi:10.1029/98JC02416, 1998.

Stroeve, J. C., Maslanik, J., and Xiaoming, L.: An intercomparison of DMSP F11- and F13-derived sea ice products, Remote Sens. Environ., 64, 132-152, doi:10.1016/S0034-4257(97)00174-0, 1998.
Stroeve, J. C., Markus, T., Meier, W., and Miller, J.: Recent changes in the Arctic melt season, Ann. Glaciol., 44, 367-374, doi:10.3189/172756406781811583, 2006.

Stroeve, J. C., Markus, T., Boisvert, L., Miller, J., and Barrett, A.: Changes in Arctic melt season and implications for sea ice loss, Geophys. Res. Lett., 41, 1216-1225, doi:10.1002/2013GL058951, 2014.

Wang, L., Wolken, G. J., Sharp, M. J., Howell, S. E. L., Derksen, C., Brown, R. D., Markus, T., and Cole, J.: Integrated panArctic melt onset detection from satellite active and passive microwave measurements, 2000-2009, J. Geophys. Res., 116, D22103, doi:10.1029/2011JD016256, 2011.

Winebrenner, D. P., Nelson, E. D., Colony, R., and West, R. D.: Observation of melt onset on multiyear Arctic sea ice using the ERS-1 synthetic aperture radar, J. Geophys. Res., 99, 22425-22441, doi:10.1029/94JC01268, 1994. 